\title{
Shipping noise in a dynamic sea: a case study of grey seals in the Celtic Sea
}

Chen, Feng

Shapiro, Georgy I

Bennett, Kimberley Ann

Ingram, Simon N

Thompson, David

Vincent, Cecile

Russell, Debbie J

Embling, Clare B

This is the accepted manuscript (C) 2016, Elsevier

Licensed under the Creative Commons Attribution-NonCommercialNoDerivatives 4.0 International:

http://creativecommons.org/licenses/by-nc-nd/4.0/

\section{(cc) BY-NC-ND}

The published article is available from

https://dx.doi.org/10.1016/j.marpolbul.2016.09.054 
Pollution Bulletin

Elsevier Editorial System(tm) for Marine

Manuscript Draft

Manuscript Number: MPB-D-16-00661R1

Title: Shipping noise in a dynamic sea: a case study of grey seals in the Celtic Sea

Article Type: Research Paper

Keywords: anthropogenic noise; marine animals; sound propagation; acoustic modelling; ocean fronts

Corresponding Author: Dr. Feng Chen, PhD

Corresponding Author's Institution: Plymouth University

First Author: Feng Chen, PhD

Order of Authors: Feng Chen, PhD; Georgy I Shapiro; Kimberley A Bennett; Simon N Ingram; David Thompson; Cécile Vincent; Debbie J Russell; Clare B Embling

Abstract: Shipping noise is a threat to marine wildlife. Grey seals are benthic foragers, and thus experience acoustic noise throughout the water column, which makes them a good model species for a case study of the potential impacts of shipping noise. We used ship track data from the Celtic Sea, seal track data and a coupled ocean-acoustic modelling system to assess the noise exposure of grey seals along their tracks. It was found that the animals experience step changes in sound levels up to $\sim 20 \mathrm{~dB}$ at a frequency of $125 \mathrm{~Hz}$, and $\sim 10 \mathrm{~dB}$ on average over $10-1000 \mathrm{~Hz}$ when they dive through the thermocline, particularly during summer. Our results showed large seasonal differences in the noise level experienced by the seals. These results reveal the actual noise exposure by the animals and could help in marine spatial planning. 

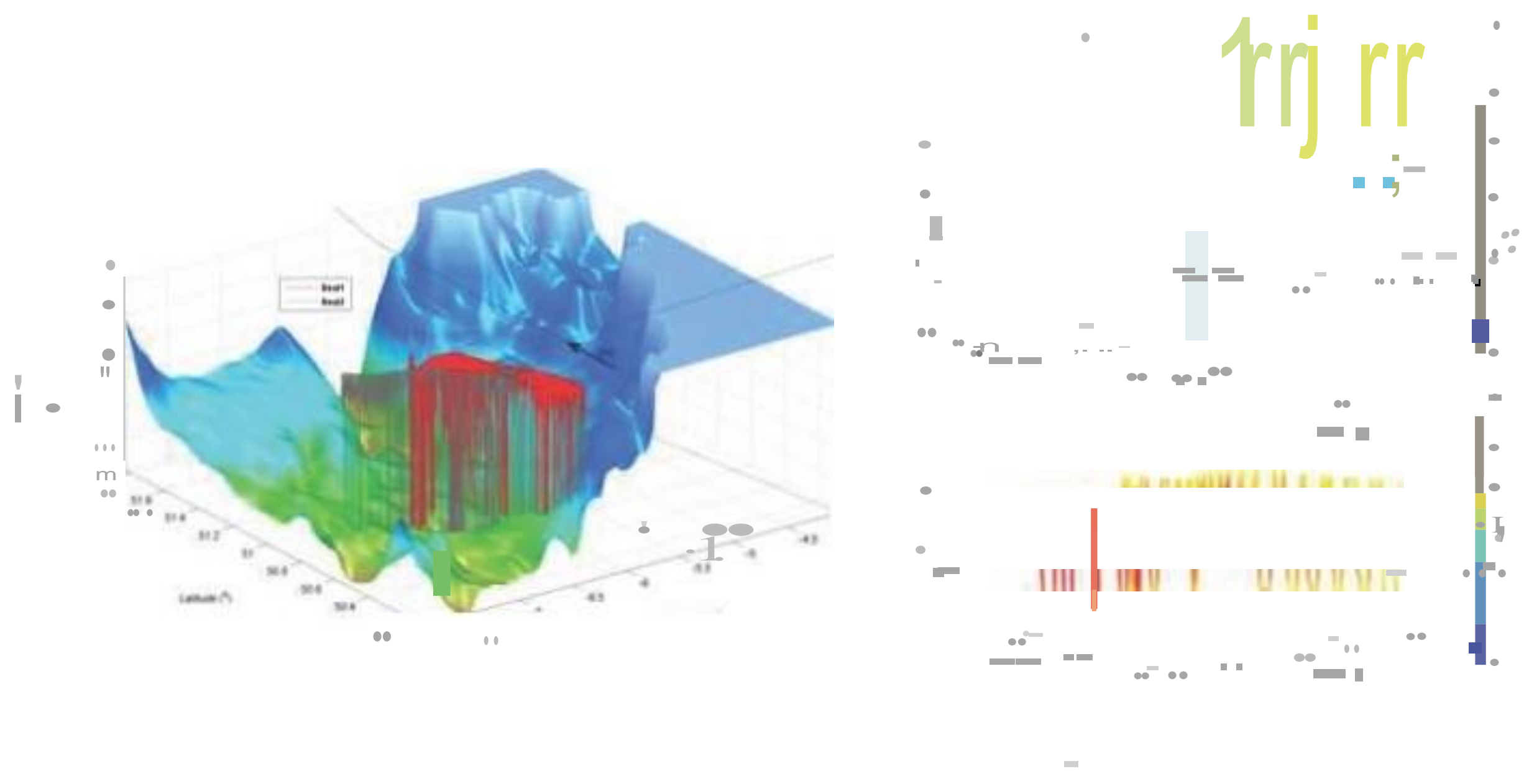
- Differences in sound level between the advanced and basic models are up to 40dB

- Sound energy propagates further by tens of kilometres in shallow seas in winter

- The model is able to estimate the sound from moving ships received by moving seals

- Sound exposure experienced by seals is highly seasonally variable

- Seals experience step changes of up to $\sim 20 \mathrm{~dB}$ (at $125 \mathrm{~Hz}$ ) across the thermocline 


\title{
Shipping noise in a dynamic sea: a case study of grey seals in the Celtic Sea
}

\author{
Chen, F. ${ }^{a}$, Shapiro, G.I. ${ }^{a}$, Bennett, K.A. ${ }^{\text {a,b }}$, Ingram, S.N. ${ }^{a}$, Thompson, D. ${ }^{\text {, }}$, Vincent, C. ${ }^{\text {, }}$ \\ Russell, D.J.F. ${ }^{\mathrm{c}}$, Embling, C.B. ${ }^{\mathrm{a}}$ \\ ${ }^{\text {a }}$ School of Marine Science and Engineering, Plymouth University, Drake Circus, Plymouth, PL4 \\ 8AA, UK \\ ${ }^{\mathrm{b}}$ School of Science, Engineering and Technology, Abertay University, Dundee, UK. \\ ${ }^{\mathrm{c}}$ Sea Mammal Research Unit, Scottish Oceans Institute, University of St Andrews, UK.

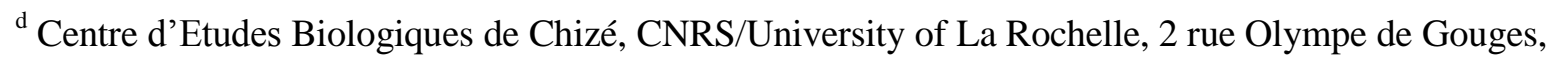 \\ 17000 La Rochelle, France.
}

Keywords: anthropogenic noise; marine animals; sound propagation; acoustic modelling; ocean fronts

\section{Abstract}

Shipping noise is a threat to marine wildlife. Grey seals are benthic foragers, and thus experience acoustic noise throughout the water column, which makes them a good model species for a case study of the potential impacts of shipping noise. We used ship track data from the Celtic Sea, seal track data and a coupled ocean-acoustic modelling system to assess the noise exposure of grey seals along their tracks. It was found that the animals experience step changes in sound levels up to $\sim 20 \mathrm{~dB}$ at a frequency of $125 \mathrm{~Hz}$, and $\sim 10 \mathrm{~dB}$ on average over $10-1000 \mathrm{~Hz}$ when they dive through the thermocline, particularly during summer. Our results showed large seasonal differences in the noise level experienced by the seals. These results reveal the actual noise exposure by the animals and could help in marine spatial planning. 


\section{Introduction}

Anthropogenic noise in the marine environment has increased significantly over the past five decades (McDonald et al., 2006). Growing evidence suggests that this increased noise is negatively impacting a range of species from crabs (Wale et al., 2013) to cetaceans (e.g. Rolland et al., 2012). Most research has concentrated on the acute impacts of loud impulsive sounds, such as pile driving, sonar and seismic air guns on acoustically sensitive species (e.g. Richardson et al., 1995). However, chronic, persistent noise, such as that from shipping, is becoming the focus of more recent research (e.g. Rolland et al., 2012; Simpson et al., 2016). Shipping noise has increased by $2.5-3 \mathrm{~dB}$ per decade over the last four decades $(30-50 \mathrm{~Hz}$; McDonald et al., 2006). This increase is particularly evident near major ports due to greater shipping density, usually concentrated in shallow shelf waters.

Noise from ships has the potential to mask the communication of acoustically active marine mammals (e.g. Williams et al 2014) and result in changes in their behaviour such as (i) reducing the communication distance between the animals (e.g. grey seal (Halichoerus grypus): Bagocius, 2015), (ii) increasing the amplitude of vocalisations (e.g. right whales (Eubalaena glacialis): Parks et al., 2011) and (iii) reducing calling rates (e.g. beluga whales (Delphinapterus leucas): Lesage et al., 1999). The mitigation of shipping noise pollution is therefore integral to marine spatial planning in the shelf seas, where anthropogenic activities are rapidly increasing (Ellison et al., 2011). The International Maritime Organisation (IMO) recently released guidelines for the reduction of underwater shipping noise (IMO 2014 MEPC.1/Circ.833). Anthropogenic underwater noise has also recently been recognised as a form of pollution in European legislation through the Marine Strategy Framework Directive (MFSD descriptor 11: 2010/477/EU). Shipping noise is principally concentrated at low (<300 $\mathrm{Hz}$ ) frequencies (Richardson et al., 1995). For low frequency noise policy requires monitoring of trends in the ambient noise level within the $1 / 3$ octave bands of 63 and $125 \mathrm{~Hz}$ (centre 
frequency), which will be studied in this paper. With chronic persistent noise, a

comprehensive approach is required since both the source (ship) and the receiver (mobile marine species) are moving through space and time, and this provides an additional challenge to assessing sound exposure.

Currently, there is insufficient observational data to support a thorough assessment of either ambient noise levels or their impacts on marine animal populations (UKMS, 2014), and there is an urgent need for detailed sound propagation predictions for complex noises and moving sources to generate and test hypotheses about their impacts on behaviour and energetics. Sound propagation modelling is an essential tool to assess the impact of shipping noise on marine mammals. The area affected by noise and the severity of the impacts depend on the frequency, duration and ability of the sound to propagate (Bailey et al., 2010). Key factors affecting sound propagation are the oceanographic and geomorphological characteristics of the surrounding region. Underwater acoustic signals do not propagate along a straight line, instead sound waves experience multiple reflections from the sea surface and seabed (Katsnelson et al., 2012). Furthermore, meso-scale features (e.g. fronts and eddies) and finescale characteristics (e.g. internal waves) can result in fluctuations of sound energy by up to 20dB (Lynch et al., 2006; Shapiro et al., 2014). Despite of their importance, these features are rarely incorporated into sound transmission models due to the lack of high resolution data on seawater parameters (e.g. temperature and salinity).

The Celtic Sea (see Fig. 1) provided the ideal location in which to investigate the use of oceanographically-referenced sound propagation models for assessing shipping noise exposure to marine animals. Shipping traffic in the Celtic Sea is heavy because it links the Atlantic with the UK coastal waters. The Celtic Sea is shallow with depths rarely exceeding $120 \mathrm{~m}$. The sea is strongly stratified with a sharp thermocline from April to November and is 
mixed in winter, and a series of bottom fronts exist during the summer (Pingree, 1980). In

addition, eddies with a typical diameter of $20-40 \mathrm{~km}$ also exist over the shelf-break region in late summer (Pingree, 1980).

Our previous study (Shapiro et al., 2014) showed the strong variability of sound propagation in the Celtic Sea due to strong seasonal variability in water column stratification. The transmission loss (hereafter TL) differs between summer and winter by as large as $\sim 20 \mathrm{~dB}$. In summer, when the source of sound is on the onshore side of the bottom front, sound energy is mostly concentrated in the near-bottom layer, resulting in step changes of TL in the water column up to $\sim 20 \mathrm{~dB}$. In winter sound from the same source is, however, distributed more evenly in the vertical. When the source is on the seaward side of the front, the sound level from a shallow source is nearly uniform in the vertical and the TL is significantly greater $(\sim 16 \mathrm{~dB}$ at $40 \mathrm{~km}$ distance) in summer than in winter. Such large seasonal differences in sound $\mathrm{TL}$ are, therefore, likely to result in significant seasonal changes in shipping noise exposure experienced by marine animals.

Assessing the effects of underwater noise on marine animals requires large databases that characterise animals' behaviour, movements and associated noise levels. Grey seals (Halichoerus grypus) are a highly tractable species which move over wide areas and feed predominantly at the benthos in shelf seas (McConnell et al., 1999; Thompson, 2012). This makes them a good choice for the reconstruction and assessment of received sound levels of animals. The movements of individuals and underwater behaviour can be tracked in fine detail using GPS-GSM (Russell \& McConnell, 2014) or satellite tags that record position and dive profiles, allowing dive by dive sound exposure to be calculated and potential behavioural or energetic consequences to be assessed. Unlike many cetaceans, grey seals do not critically depend on hearing to survive, but they are highly vocally active in air and in water with a 
substantial repertoire (Asselin et al., 1993). They use sound and vibrations in aggression,

mating and in mother-pup bonding (Bishop et al., 2015) and the repertoire extends across a wide range of frequencies though most are typically less than $3 \mathrm{kHz}$. They can also use sounds passively in foraging scenarios (Stansbury et al., 2015). Pinnipeds have anatomical adaptations that mean they are well-adapted to hearing in water, and have hearing ranges from very low frequencies $\sim 100 \mathrm{~Hz}$ (Kastak and Schusterman, 1998) to high frequencies $\sim 30 \mathrm{kHz}$ (Cunningham et al., 2016). It is therefore likely that shipping noise is within the hearing range of grey seals.

The aim of this paper is to assess the shipping noise exposure experienced by grey seals along their tracks, and how this exposure varies seasonally. We used two grey seals and the Celtic Sea for this case study. However, we believe that the general outcomes of this research are applicable to other shelf seas and other animals, where both the source (ship) and receiver (marine animal) move in space and time. To achieve this we used a state-of-the-art ocean and acoustic propagation model (Shapiro et al., 2014) populated with GPS tracks and dive data from grey seals, and real-time AIS shipping data from winter and summer.

\section{Materials and methods}

\subsection{Shipping data}

The accurate modelling of shipping noise first requires detailed information on shipping in order to estimate the source levels (SL) of ships. The realistic operational information and ship properties were extracted from an Automatic Identification System (AIS) database through a web-based ship tracking database (http://www.marinetraffic.com/), which are now widely used for shipping noise studies (e.g. Merchant et al., 2012; Erbe et al., 2012). Recorded vessel parameters, including vessel name, type, dimension, operational speed, location and time, are updated at most every 2 minutes. For a moving ship the operational 
speed and location were linearly interpolated to 1 s interval in time. An example of a real track

of a commercial cargo ship (MMSi: 353633000) with length 155m and average speed 15.5 knots in August 2010 is shown in Fig. 1, located in the heavily used shipping lane in the Celtic Sea.

The narrow band spectrum of the source level (SL) from a ship was calculated using the classic Ross, (1976) power law model:

where is the ship's speed in knots and is the ship's length in feet. is a reference spectrum defining an average ship as one with a speed of 12 knot and a length of 300 feet. and are additional length correction which can be found from Breeding et al. (1996). This is an empirical model based on a large number of measurements, which is also used by worldwide noise models such as RANDI (Breeding, et al., 1996). Given that the predominant bandwidth for shipping noise ranges from $10 \mathrm{~Hz}$ to $1000 \mathrm{~Hz}$ (although it does extend into the higher frequencies at least up to 40kHz (Viers et al., 2016)), the modelled narrow band spectrum from equation (1) was integrated into standard 1/3 octave central frequency spectrum between $10-1000 \mathrm{~Hz}$, giving the representative source level (SL) of the ship noise in 1/3 octave band. Three ships were selected in this study: one was used to map sound exposure levels (which is defined as the received sound level integrated of the time of exposure, hereafter SEL, see section 2.4.3 for details) in two seasons, and two ships were used to calculate received root-mean-square sound pressure levels (hereafter SPL) and SEL of Seal1 and Seal2 respectively (see details in table 1). The source level spectrum, which was calculated using equation (1) is shown in Fig. 2. The sound spectrum showed a 'hump' at 10 to $100 \mathrm{~Hz}$, and above $100 \mathrm{~Hz}$ sound levels decrease, which is a typical feature revealed in previous observations (e.g. Ross, 1976; McKenna et al., 2012). The peak of sound source 
level occurred at $\sim 50 \mathrm{~Hz}$ and they are $\sim 185 \mathrm{~dB}, \sim 183 \mathrm{~dB}$ and $\sim 173 \mathrm{~dB}$ depending on the lengths and operational speeds of the ship.

\subsection{Ocean-acoustic modelling system}

A coupled ocean-acoustic modelling system, implemented in the Celtic Sea by Shapiro et al. (2014), was used to calculate TL of sound energy. This modelling system combines an oceanographic model (POLCOMS) with an acoustic propagation model (HARCAM).

POLCOMS is a three-dimensional (3D) model that has been used successfully for modelling temperature and salinity in different regions of the world ocean and has been used operationally by the UK Met Office for the European Shelf seas (Bell, 2012). The main features of POLCOMS are available from Holt and James (2001), and are therefore not repeated here. The implementation and validation of POLCOMS in the Celtic Sea has been performed in previous studies (Shapiro, 2011; Chen et al., 2013), which demonstrated that the mean error of the model in predicting temperature over the whole 3D domain was approximately $0.72^{\circ} \mathrm{C}$ against observational data. The model was constructed with $2 \mathrm{~km}$ horizontal resolution and 30 vertical layers, which were used to provide high-resolution hourly temperature and salinity data for the acoustic propagation model.

HARCAM is an acoustic model which is used as a transmission loss engine of the Naval Tactical Decision Aid WADER system, a sonar range prediction and global ocean information system used operationally by the UK Royal Navy. The model has been validated by the U.K. Ministry of Defence (MOD) over a variety of frequencies $(10 \mathrm{~Hz}-500 \mathrm{kHz})$ in both shallow and deep waters (Etter, 2001). The model has been also verified by comparison with other similar models (Etter, 2001) and UK MOD benchmark TL data. HARCAM calculates the acoustic signal TL and the level of sound exposure at a distance from a sound source. Unlike the simpler and range-independent models, that assume the oceanographic and 
sediment parameters are identical over the propagation range, the HARCAM model is able to

take into account the spatial variability of environmental parameters. The setup of the model is similar to that of Shapiro et al (2014), although the sediment data used in this study (see Table 2) covers a wider range of sediment types.

\subsection{Seal tag data}

We explored the tracks of adult and pup grey seals tagged in Wales (Ramsey Island,

Pembrokeshire) in 10/2010 - 10/2011 and France (the Iroise Sea) in 08/2010 - 12/2012 to identify animals that spent some of their time in the region identified in Fig. 1 during a period when AIS data were also available. Grey seals were caught on or near haul outs and tags attached using the methods described previously (McConnell et al., 1999) under Home Office licence number 60/4009 and in accordance with the UK Animals (Scientific Procedures) Act 1986, and licence number 11/873/DEROG by the French ministry of Environment. The telemetry devices were Sea Mammal Research Unit GPS-GSM phone tags. GPS-GSM phone tags provide GPS quality locations and only require the animal to surface for less than $1 \mathrm{~s}$ to obtain an accurate location fix, through use of the Fastloc system. Erroneous locations do occur and these were removed using the thresholds of a number of satellites and residual error (Russell \& McConnell, 2014). Following these cleaning procedures 95\% of locations have distance error of less than 50m. Tags record whether the animal is wet or dry and contain a pressure sensor to record dive depth. The GSM- GPS phone tags used in this study record every dive and transmit almost all recorded dives, which results in up to 90 locations per day depending on the specific tags. Behaviour was recorded as a 'dive' when the sensor was wet and the pressure sensor recorded a depth below a $1.5 \mathrm{~m}$ threshold for 8 seconds. Dives ended when the sensor was dry, or when the pressure sensor recorded depth above $1.5 \mathrm{~m}$. Location and behavioural information were stored on board in the tag until transmission. Data were 
transmitted by a quad band GSM mobile phone module when the animal came within range of a receiver.

One seal from each data set spent some of its time in the shipping lane area in summer and winter respectively and the relative positions between ships and seals are given in Fig. 1. Seal 1 corresponds to the summer condition whilst Seal 2 is for the winter. Two segments (arrows in Fig. 1) were extracted from the seal track data based on the time when the ship started travelling northwards from the southernmost point of the shipping lane. The parameters of the seals were summarised in Table 1. As the location data were less frequently recorded than dive data, in order to obtain the location information for each dive the locations were interpolated between known GPS locations by assuming straight movements at a constant speed. Specifically, the horizontal speed of seals was first calculated based on the adjacent GPS location points for which latitude, longitude and recorded time were available. Subsequently the location data were linearly interpolated to an interval of 1s. Dive parameters included total dive time, maximum depth of dive, and depths at nine even spaced time points. The depth data were also interpolated to 1s interval. By doing so, the seal position was characterised by location data and vertical depth at an interval of 1s. The sound exposure in 3D space experienced by the seals was calculated by linking the ocean-acoustic modelling system and seal track parameters, in which seals and ships were modelled as moving receivers and sources simultaneously.

\subsection{Calculation of shipping noise parameters}

\subsubsection{Transmission loss over transect A}

The common approach to calculating acoustic TL is to consider a two-dimensional (2D) problem (range and depth) assuming that the azimuthal dependence is small and the source is treated as an omnidirectional monochromatic point, a single point where source energy is 
concentrated and sound energy radiates spherically through all directions (Katsnelson, et al.,

2012). A transect (A in Fig. 1) that crosses the bottom temperature front was selected to perform the TL calculation for summer and winter. The ship (MMSi: 353633000) travelled northwards through the shipping lane on 5th August and 5th December in 2010. These two days were thus chosen for transect A, giving the summer and winter conditions respectively. Transect A shows the sound propagation pattern in 2D space, in which sound energy propagates from the ship to the seals' location. Calculations were carried out for $125 \mathrm{~Hz}$ since it is one of two $1 / 3$-octave bands ( 63 and $125 \mathrm{~Hz}$ ) proposed to be monitored by MSFD and is believed to be within the hearing range of pinnipeds such as grey seals (Kastak \& Schusterman, 1998; Cunningham et al., 2014).

\subsubsection{Comparison to generic spreading models}

Generic basic spreading models (e.g. Bailey et al., 2010; Erbe et al., 2012) are a simplified way to assess the TL for anthropogenic noise, which were sometimes used in bioacoustics studies. In this study we tested the difference between the more accurate HARCAM and basic spreading models to assess the level of errors introduced by the simplification of the TL process in basic models. The basic spreading models that were used for comparison are , where is a factor for spreading loss, $\alpha$ is the absorption coefficient and is the range. is defined by 10, 20 and 15 (e.g. Bailey et al., 2010; Erbe et al., 2012), representing the cylindrical spreading, spherical spreading and intermediate empirical spreading respectively. The absorption coefficient $\alpha$ is estimated using the formulas from Francois and Garrison (1982).

\subsubsection{Sound exposure level of ships}

SEL is considered to be an exposure metric for non-pulse sound (such as shipping noise) because it considers the cumulative effect of sound energy over time (Southall et al., 2007). In 
order to simulate the spatial pattern of the noise field in 3D space, we calculated the multitransect TL fields generated by a point source, with an azimuthal resolution of $2.5^{\circ}$.

Received levels (RL) of receivers were estimated using the sonar equation:

where SLis the source level in $\mathrm{dB}$ re $1 \mu \mathrm{Pa} @ 1 \mathrm{~m}$ predicted from equation (1) and TL is calculated by HARCAM. The source depth (SD) for all calculations is deployed at $7 \mathrm{~m}$, a typical depth of ship propellers (McKenna, et al., 2012). Accordingly, the RL at 1/3 octave central frequencies can be obtained using this equation.

SEL is originally defined by,

where is the received mean square pressure and is the reference pressure of $1 \mu$ pa. In order to calculate the SEL when a ship covers the entire shipping route across the Celtic Sea (as indicated by the solid line in Fig. 1), an approximate discretisation was adopted here by,

Taking the spectrum of the SLinto account, the received mean square pressure was calculated by,

where is the number of central $1 / 3$ octave band frequencies between 10 and $1000 \mathrm{~Hz}$ is the individual received pressure derived from equation (2), where the RL in $\mathrm{dB}$ were converted into pressure. is the duration in seconds between two time points sampled along the ship track. 


\subsubsection{Sound exposure of seals}

Sound exposure levels received by seals were presented in SPL averaged over a frequency bandwidth of $10-1000 \mathrm{~Hz}$, and cumulative SEL. SPL is also an appropriate metric for quantifying exposure to non-pulse sounds, and is defined as the root mean square pressure expressed in decibels (Southall et al., 2007). To determine the SPL of the seals along their travelling path, ship and seal were treated as a moving source-receiver pair, between which TL was calculated at a time step of 1s using the HARCAM model. At each time step the RLs in a 1/3 octave band were calculated using equation (2) and converted to pressures. The mean square pressure was then obtained by finding the mean of the pressures in $1 / 3$ band and converted back to decibels. Cumulative SEL was calculated using equation 3.

\section{Results}

\subsection{Transmission loss under different seasonal conditions}

As shown in Fig. 3a and Fig. 3b, the water depth of transect A varied from $\sim 30 \mathrm{~m}$ to $\sim 90 \mathrm{~m}$ and the temperature pattern changed significantly between two seasons. In winter the water column was well mixed vertically with only slight variations of temperature $\left(\sim 0.3^{\circ} \mathrm{C}\right)$ in the horizontal direction, while the intense thermocline and the associated bottom front were well developed in summer. The subsurface front was located at the range $\sim 9 \mathrm{~km}$ from the source whilst the thermocline existed at a water depth of $\sim 25 \mathrm{~m}$ (see Fig. $3 \mathrm{a}$ ). The front spatially separated the water into an onshore mixed water and an offshore strong stratified area, leading to a temperature difference of $\sim 3^{\circ} \mathrm{C}$ across the front. However, the vertical contrast of temperature increased dramatically on the offshore side of the front, reaching as much as $\sim 7^{\circ} \mathrm{C}$ across the thermocline.

Fig. $3 \mathrm{c}$ and $3 \mathrm{~d}$ illustrate the TL fields of transect A for summer and winter, in which distinctive features from different seasons can be seen. In winter, the TL reduced with range 
from the ship with a relatively low rate (see Fig. 3d). The sound energy was relatively evenly

distributed vertically through the water column, giving a TL of $\sim 75 \mathrm{~dB}$ at a range of $40 \mathrm{~km}$. In summer, sound energy varied little vertically to around $8 \mathrm{~km}$ from the source (see Fig. 3c). However, beyond $8 \mathrm{~km}$, most of the sound energy was directed down into the bottom water below the thermocline, and propagated more efficiently in this deeper water. This pattern of propagation is due to both the descending bathymetry, which reduces the grazing angles of the acoustic rays at the sediment interface, hence lower bottom loss, and to the strong sound speed gradient at the thermocline, which prevents the acoustic rays from penetrating the thermocline upwards. In the upper layer the acoustic energy decayed rapidly at the front $(\sim 9 \mathrm{~km})$, showing a typical TL difference of $\sim 20 \mathrm{~dB}$ between the upper and lower layers which was not present in winter. An upper quiet zone was thus formed in summer, with the boundary following the thermocline. This caused a strong vertical step change of the TL at the interface of the thermocline in summer, reaching as large as the seasonal difference $\sim 20 \mathrm{~dB}$. The propagation range was, therefore, significantly reduced in the upper layer during summer.

The TL cut-off of $70 \mathrm{~dB}$ in the upper layer, for example, can propagate $\sim 40 \mathrm{~km}$ in winter but only $\sim 12 \mathrm{~km}$ in summer. Below the thermocline the broad pattern of the TL was, however, very similar in both seasons although small differences were predicted to exist locally.

\subsection{Testing the difference in performance between two sound propagation models}

Fig. 3e and Fig. $3 \mathrm{f}$ shows the comparison of TL of transect A at a water depth of $10 \mathrm{~m}$ between HARCAM and three generic spreading models in summer and winter. In summer the TL calculated by HARCAM was between the $20 \log$ and $15 \log$ models to the range $\sim 23 \mathrm{~km}$, subsequently following the trend of the $15 \log$ model. The $20 \log$ overestimated the TL by $\sim 4-$ $8 \mathrm{~dB}$ at shorter range $(<15 \mathrm{~km})$. Large differences in $\mathrm{TL}(\sim 10 \mathrm{~dB}-\sim 40 \mathrm{~dB})$ were found between 
HARCAM and the 10log model, increasing over the travel distance of the sound. In contrast to the summer time, in winter the $15 \log$ matched with HARCAM very well in such vertically mixed water. However, TL from $10 \log$ was predicted to be lower than that of HARCAM by $\sim 20 \mathrm{~dB}$ while TL calculated by the $20 \log$ model was higher by $\sim 20 \mathrm{~dB}$.

\subsection{Sound exposure level for grey seals moving near the shipping lane}

Fig. 4 shows the SEL for the ship (MMSi: 353633000) at two water depths (15m and 50m)

for summer and winter. The highest SEL existed along the shipping lane and the surface layer was always louder than the bottom layer at various scales, depending on the latitude of the shipping lane. The spatial pattern of the SEL in summer was more complicated than that in winter due to complex water column conditions (such as stratification, fronts and eddies). A notable feature was that sound energy could propagate much further or has higher intensity at a defined location during winter.

The magnitude of the difference in SEL increased with distance from the shipping lane, reaching $\sim 10 \mathrm{~dB}$ near the Bristol Channel for example. The propagation range was compressed dramatically in summer when the intense thermocline and bottom front developed, and the discrepancy for a specific threshold (e.g. $140 \mathrm{~dB}$ ) was up to $\sim 60 \mathrm{~km}$ shorter than that in winter.

\subsection{Calculated sound level during diving in grey seals}

Fig. 5a shows the relative distance between seal and ship against the travelling time of the seal while Fig. 5b illustrates the SPL $(10-1000 \mathrm{~Hz})$ at each diving depth for Seal1. 69 dives occurred within $\sim 10525$ seconds and each dive was numbered as shown in Fig. 5b. The black arrow marked the time point when the ship crossed the bottom front from onshore to offshore. As seen in Fig. 5b, the sound levels perceived by Seall were predicted to be highly variable in time and with water depth. Sound intensity was always low $(\sim 65-75 \mathrm{~dB})$ when the seal 
cruised near the sea surface (above $1.5 \mathrm{~m}$ water depth). This is due likely to scatterings of

sound energy at the surface boundary. The SPL of many diving profiles exhibited strong dependence on depth, showing frequent step changes in sound level. Taking the $6^{\text {th }}$ dive for instance, the change of SPL was as large as $\sim 15 \mathrm{~dB}$ when the seal dived from $20 \mathrm{~m}$ to $35 \mathrm{~m}$, with higher sound intensity $(\sim 95 \mathrm{~dB})$ in the bottom layer. This occurred during the case of downslope sound propagation in summer described in Fig. $3 \mathrm{c}$ in which a strong TL step change in the vertical direction occurred at the interface of the thermocline and sound energy was trapped mainly below the thermocline. From 0 to $\sim 3100$ seconds, when the ship was on the onshore side of the subsurface front, there were 21 dive profiles in total, including 20 shallower diving associated with relatively lower sound levels and closer distance to the ship, and 1 bottom dive, which was marked by number 6 . In contrast, from $~ 3100$ to 10525 seconds when the ship was on the offshore side of the bottom front, sound level reduced as the relative distance between seal and ship increased and a strong step change in the sound level, as observed in the $6^{\text {th }}$ dive profile, disappeared. As a result, it was predicted that when the seal dived into the bottom layer the sound energy perceived by the seal can be lower by up to $\sim 15 \mathrm{~dB}$, e.g. by comparing dive profile 27 to 6 . More frequent deeper dives associated with lower noise levels occurred down to the seabed from $\sim 3100$ to $10525 \mathrm{~s}$.

Fig. 5c was constructed in the same way as Fig. 5b, with the water column parameters being replaced by winter temperature and salinity for noise TL calculation. This allowed direct comparison of received sound levels between summer and winter. The overall seasonal difference in received sound levels was higher by approximately $10 \mathrm{~dB}$ in winter. An obvious feature can be seen that strong step changes of sound energy in water depth disappeared (e.g. diving profile 6). From 0 to 3100 seconds during which the ship was located on the onshore side of the front and shallower diving occurred more frequently, the sound energy received by 
Seal1 above $\sim 30 \mathrm{~m}$ in water depth was greater by $\sim 15-20 \mathrm{~dB}$ than that of summer. Below

$30 \mathrm{~m}$ the predicted sound level was, however, almost the same.

Fig. 6 shows the noise pattern for Seal2 in winter when the water column was well mixed. Overall, the received SPL over its diving path for Seal2 was higher by $~ 20 \mathrm{~dB}$ than that of Seal1 due primarily to the stronger source level for Seal2 (see Fig. 2) and different environmental parameters. At the top and bottom boundary layers where sound interacts, sound level was, as expected, to be lower ( 10dB for this case) than that of the intermediate water layer due to scattering and reflection. In contrast to Seal1, the sound level experienced by Seal2 exhibited weak variability in diving depth, among a range of different dive profiles. Seal2 started shallower diving when it approached the closest point (at $\sim 4900$ seconds) to the ship, and returned to bottom diving at $\sim 7900$ seconds when the ship was moving away.

Similar to Fig. 5, Fig. 6c shows the predicted noise level of Seal2 where summer temperature and salinity were used for TL calculation. When the ship was on the onshore side of the front many step changes in sound level were observed among bottom diving profiles. The magnitude of the step changes reduced with the decrease of the distance between Seal2 and the ship, e.g. from $\sim 15 \mathrm{~dB}$ in profile 1 to $\sim 3 \mathrm{~dB}$ in profile 19 . After the ship crossed the front, strong step changes in sound level disappeared and the overall sound level was $\sim 10 \mathrm{~dB}$ lower than that of winter.

The cumulative SEL for Seal1 and Seal2 is presented in Fig.7, showing a nearly constant seasonal difference of $\sim 5 \mathrm{~dB}$ for two seals. In summer a step change of SEL can be also observed when the seal travelled from 0 to $\sim 3 \mathrm{~km}$. The difference of realistic SEL between summer (red) and winter (blue) reached as much as a $\sim 20 \mathrm{~dB}$, due primarily to the difference in the source level and the changes of water column parameters. 


\section{Discussion}

We have shown that in order to get a reasonable estimate of the shipping noise exposure experienced by marine animals, the acoustic model has to take into account the complex 3D structure of temperature and salinity fields in the ocean. The ocean-acoustic modelling system used in this study was able to assess the sound level exposure when the ships and animals were moving simultaneously. The results demonstrated that there was a strong seasonal difference in the sound level exposure due to the seasonal variation of ocean parameters. There was also a strong variability in the exposure level at different dive depths, in particular during summer.

\subsection{Seasonal differences in sound propagation}

Using the combined ocean-acoustic modelling system, populated with high resolution water column data, sediments, bathymetry and sea surface wind speed, we have shown a significant difference in noise propagation in summer and winter around an important shipping lane in the Celtic Sea. In winter the water was well mixed, and the TL was only weakly dependent on water depth: the variability in the level of TL was typically less than $5 \mathrm{~dB}$ (see Fig. 3d). By contrast, in the presence of a thermocline and bottom fronts (Fig. 3c), when the source was located on the onshore side of the bottom front, sound energy was trapped below the thermocline. As a result, a quiet area above the thermocline was formed and the TL difference at a frequency of $125 \mathrm{~Hz}$ could be as large as $\sim 20 \mathrm{~dB}$ in the vertical water column, which is comparable to the study by Shapiro et al. (2014) in which the vertical TL discrepancies were $\sim 15 \mathrm{~dB}$ at a frequency of $300 \mathrm{~Hz}$ and $\sim 20 \mathrm{~dB}$ for $1000 \mathrm{~Hz}$ in the Celtic Sea. The mechanism that forms the non-uniform propagation pattern in summer has been discussed in detail by Shapiro et al. (2014). 
The sound distribution mapped in this study demonstrated a strong variability in time and

space (see Fig. 4). The combined effects of ship movements relative to the front and the sound propagation characteristics of the water affect the value of SEL. The effect of downwards refraction, which is caused mainly by stratification in the water column, dominated the sound distribution and led to a significant reduction of the propagation range in summer. As a result, the SEL is highly dependent on the formation of the seasonal stratification that develops in early summer and breaks down in the later autumn (Pingree, 1980). In contrast to the downwards refraction effect, the bottom front produces a more localised effect that is dependent on the relative position of the front and its source. For instance, in the south of the shipping lane where the bottom fronts existed, the propagation range of noise was increased by $\sim 15 \mathrm{~km}$, see Fig. 3c and Fig. 4c.

One of the monitoring schemes proposed by MSFD is to monitor trends in the ambient noise level within the 1/3 octave bands 63 and $125 \mathrm{~Hz}$ (MSFD-GES, 2012). In this study we have followed this scheme and clearly shown a strong influence of water column conditions on noise distribution, which would affect any receivers. It is therefore suggested that the seasonal variability of the water column should be taken into account in the documentation of noise trends.

\subsection{Differences in sound propagation model performance}

Our study showed that in order to achieve representative results on the noise exposure of marine mammals, acoustic models should not ignore variation in temperature and salinity within the water column, as was the case with some older basic bioacoustics studies (e.g. Richardson, et al., 1995). Our comparison between HARCAM and basic spreading models has shown that the cylindrical spreading model $(10 \log )$ failed to estimate the TL in such shallow water, because the difference between the two models was as large as $\sim 20-\sim 40 \mathrm{~dB}$ 
(Fig. 3e). The intermediate empirical spreading model (15log) underestimated the TL by up to

$\sim 20 \mathrm{~dB}$, while the spherical spreading model $(20 \log )$, which is generally used for deep waters (Jensen et al., 2011), overestimated the TL in the Celtic Sea with a maximum value of $~ 20 \mathrm{~dB}$. Significant errors produced by the basic models were also evidenced by field measurements in coastal water undertaken by Pine et al. (2014), who demonstrated a disparity between the theoretical spherical spreading model and field measurements of up to $41 \mathrm{~dB}$. Significant errors produced by the basic models were confirmed by Madsen et al. (2006), who used onboard acoustic recording tags. The above analysis suggests that the basic spreading models should not be used in dynamic shelf seas as they do not simulate the TL fields accurately.

\subsection{Noise exposure of tracked seals}

Zones of noise influence (Richardson et al., 1995) are spatial representations which classify noise distribution based on the estimated severity of injury. These zones are centred at the source, where animals are expected to receive the most severe injury, and decrease in severity with increasing distance from the source. The SEL characteristics calculated in this study suggest that the radius of these zones is strongly affected by season and water depth. We have also shown that the seasonal difference in sound propagation, and hence the size of the zone of influence, depends on the value of the threshold; the lower the threshold value, the greater the seasonal difference. As seen in Fig. 4, the difference in the size of the area covered by the $150 \mathrm{~dB}$ contour line is relatively small between summer and winter, while the size of the area covered by the threshold of $140 \mathrm{~dB}$ is approximately $4-5$ times greater. Such attenuation in sound suggests that the zones of audibility and behavioural response are more strongly influenced than injury zones, within which noise is strong enough to cause discomfort or tissue damage to animals. 
Auditory masking, which is a reduction of the animals' ability to detect biologically important

sounds in the presence of noise, might affect their communication, energy budget, behaviours and fitness, and hence their survival. Acoustical surveys in the Baltic Sea by Bagocius (2015) showed that local shipping noise had high masking potential for grey seal communication calls. In this study, the rups call type (in recorded grey seal vocalisations within $0.1-5 \mathrm{kHz}$ range) was shown to have an average sound level of $71 \mathrm{~dB}$ at a centred frequency of $256 \mathrm{~Hz}$, and maximum sound level of $103 \mathrm{~dB}$. On average, the calculated SPLs in our study were $\sim 60 \mathrm{~dB}-\sim 90 \mathrm{~dB}$ and $\sim 85-\sim 97 \mathrm{~dB}$ for Seal1 and Seal2, respectively, and therefore significantly overlap the vocalisation signals observed by Bagocius (2015). Ship noise thus has a potential to mask the auditory communication of grey seals, especially in winter. For example, Seal 2 would have to raise its signal intensity to be audible to its conspecifics, which may have energetic consequences. Permanent hearing damage (PTS) to pinnipeds exposed to non-pulse sound such as shipping noise is predicted to occur when the peak SPL of noise is $218 \mathrm{~dB}$ and above, or the M-weighted SEL is $203 \mathrm{~dB}$ and above. The exposure criteria for temporary hearing damage (TTS) are 212dB for SPL and 183dB for SEL (Southall et al., 2007). However, the loudness of the sounds in our study did not reach levels at which either permanent or temporary damage would be expected to occur for seals (e.g. Hastie et al., 2015).

Cliff-based surveys have shown that seals are less likely to be sighted when vessel traffic is high (Anderwald et al., 2013). Our study had insufficient data to determine firmly whether seals showed behavioural avoidance of shipping within the available tracking data. Of all the seals tracked, very few used the area surrounding the shipping lane, so that finding a portion of track that overlapped in real time and space with that of a real ship was challenging. One possibility is that seals avoid this area altogether, possibly as a result of noise or other disturbance, or because the area is not a good foraging ground. Previous research overlaying 
VMS data and seal tracks in Ireland has shown a lack of overlap between seal habitat usage

and fishing effort (Cronin et al., 2010), which reflects either the targeting of different areas by seals and fishermen, or active avoidance by seals. However, seal usage maps based on tracks from years in which AIS data were not available show high seal usage in the same region as the shipping lane (Thompson, 2012). Further work on the overlap between seal usage from telemetry data and shipping lanes would be informative, particularly in assessing potential winter versus summer differences in use which may be associated with sound.

Received sound at the deepest portion (>90\% dive depth) of the dive may have the greatest impact on seals, since this is where they spend most time (40-45\% of total dive time) on a dive-by-dive basis (Thompson, 2012). An analysis of cumulative time spent at depth in areas predicted to be noisy and quiet using our approach would be valuable in estimating any potential long term impacts.

The behaviour of seal pups in response to shipping noise is of particular interest because they are weaned abruptly on land and thus learn to forage without parental guidance (Bennett et al., 2010), and have higher mass specific metabolic costs than adults (Sparling \& Fedak, 2004). The disruption of foraging behaviour may have energetic consequences for individuals, which, depending on the magnitude of the effect, could influence survival. Whether such reduced survival would have population consequences is dependent on the proportion of the population exposed and the predominant age class affected. Understanding the sound transmission of shipping noise in the Celtic Sea is therefore of additional importance because the seal populations in Wales, Ireland, Cornwall and France are relatively small (e.g. Vincent et al., 2005; Leeney et al., 2010). Louder background noise in winter and prior to the development of a thermocline may be of biological consequence particularly for pups, which 
mostly enter the sea for the first time to learn to forage during winter and early spring in this population.

One interesting feature of the predicted received sound here is the step changes that seem to occur during the summer within and between dives. We have studied these effects caused by a single ship. The extent to which these step changes are masked or amplified by the inclusion of sound produced by multiple ships requires investigation. However, step changes during the rapid descent or ascent phase could deter animals from performing subsequent dives to below the depth at which the step change was experienced. The seal track avoiding a loud nearbottom area shown in Fig. 5b (see the time range between 751 and 3759 seconds) would support this hypothesis. We have insufficient data to confirm these hypotheses at present, but extension of our modelling approach to areas with greater telemetry data overlap would allow greater exploration of these possibilities. Our approach may allow us to examine whether seals avoid specific depths after sound exposure, and whether they show heading changes or alter dive characteristics in response to parameters including received sound, given time of year and activity and/or physiological state (Ellison et al., 2011). This requires the simultaneous modelling of sound produced by all ships in the region at any given time, ambient noise caused by waves and wind and the inclusion of data from multiple seals. Additional tagging efforts in South Wales or Northern Cornwall would help address the relative dearth of seal tracking data in the Celtic Sea.

Although the long-term or chronic effects from shipping noise on marine life are still largely unknown and have not yet been incorporated into management decisions (Ellison, et al., 2011), there is increasing concern about the detrimental impacts in chronically exposed areas. For example, in a unique study, North Atlantic right whales (Eubalaena glacialis) appeared to have reduced faecal stress hormone (cortisol) levels after the reduction in shipping traffic 
following the events on $11^{\text {th }}$ September 2001 (Rolland et al., 2012). This type of effect is

difficult to assess under normal conditions, where shipping noise levels are constant and pervasive. Environmental conditions can lead to significant sound propagation anomalies, thus increasing the uncertainty surrounding the predictions of noise impacts. Including detailed environmental conditions in shipping noise management would aid our understanding of how the dynamic acoustic environment affects the noise field, and thus marine organisms. It would also enable the optimisation of noise mitigation strategies and the designation of MPAs. Coupled ocean-acoustic models similar to those used in this study are an effective and reliable method that can simulate the sound field over large areas and long periods of time. This facility is important for both biological applications and anthropogenic noise estimation, especially for continuous acoustic events in wide geographic areas (e.g. shipping noise), because direct measurement can be impractical and/ or expensive. In addition, the long distance movements of seals (and other large, mobile predators), particularly the less predictable dispersal movements of pups (Bennett et al., 2010; Thompson, 2012), make a modelling approach to estimate sound exposure quite attractive. Even when viable animalborne sound sensors have been developed, our approach will help compare the sound profiles of areas actually used by animals for different activities with less frequented areas. This will allow us to better evaluate the impacts of anthropogenic noise on habitat availability and quality, and to tease apart shipping noise from other sources of background noise.

\section{Summary}

We have selected the Celtic Sea and grey seals as a case study and shown how the seasonal variability in the hydrological structure of the water column affects the exposure levels of grey seals to shipping noise. This effect is likely to influence any free-ranging highly mobile marine mammals in shelf seas. In summer the areas of high noise exposure by animals were situated below the thermocline when the ship was located on the onshore side of the oceanic 
front. These were areas located above the thermocline when the ship was on the offshore side

of the front. The difference in the received sound level between the surface and near-bottom parts of the water column was as high as $\sim 20 \mathrm{~dB}$. Shipping noise propagated much further (by tens of kilometres) in winter than in summer. Furthermore, this study showed strong step changes of the sound perceived by seals during their descent and ascent through the water column. Since seals are bottom foragers, the step-change in shipping noise sound exposure may have negative impacts on their foraging behaviour. Although these results relate to a single ship, they show the value of including oceanographic features in sound transmission models and form the basis for more complex simulations of multiple ships. The approach established in this study can be applied to other species and other shelf seas, for instance, to generate biological and noise databases characterising the effects that shipping noise has on marine mammals. It is only through a more realistic understanding of the exposure of animals to ship noise, in which source and receiver are both moving, that we can set appropriate management and mitigation targets.

\section{Acknowledgements}

This study was supported by the EU (via PERSEUS grant FP7-OCEAN-2011-287600 and MyOcean SPA.2011.1.5-01 grant 283367). In addition, C.B. Embling was supported by the 2014 SoMSE Plymouth University Small research grant. D.J.F. Russell and D. Thompson were supported by the National Capability funding from the Natural Environment Research Council to the Sea Mammal Research Unit (grant no. SMRU1001). C. Vincent was supported by the Parc naturel marin d'Iroise and Région Poitou - Charentes. The authors are also grateful to Ocean Acoustic Developments Ltd and personally to Mr John J. Hodgson for provision of HARCAM software and advice for its best use, and to http://www. marinetraffic.com/for provision of ship AIS data. 


\section{References}

Anderwald, P., Brandecker, A., Coleman, M., Collins, C., Denniston, H., Haberlin, M.D., O’Donovan, M., Pinfield, R., Visser, F., Walshe, L., 2013. Displacement responses of a mysticete, an odontocete and a phocid seal to construction - related traffic. Endangered Species Research. 21: $231-240$.

Asselin, S., Hammill, M.O., Barrette, C., 1993. Underwater vocalizations of ice breeding grey seals. Can J Zool 71: 2211 - 2219.

Bagocius, D., 2015. Potential Masking of the Baltic Grey Seal Vocalisations by Underwater Shipping Noise in the Lithuanian Area of the Baltic Sea. ENVIRONMENTAL RESEARCH, ENGINEERING AND MANAGEMENT. 4(70): 66 - 72.

Bailey, H., Senior, B., Simmons, D., Rusin, J., Picken, G., Thompson, P.M. 2010. Assessing underwater noise levels during pile driving at an offshore windfarm and its potential effects on marine mammals. Marine Pollution Bulletin. 60, 888 - 897.

Bell, M., 2012, Ocean Forecasting http://www.metoffice.gov.uk/media/pdf/f/d/MOSAC_17.7_MBell.pdf.

Bennett, K. A., McConnell, B. J., Moss, S. E. W., Speakmand, J. R., Pomeroy, P. P., Fedak, M. A., 2010. Development of diving capabilities of grey seal pups: costs and benefits of the postweaning fast. Physiol Biohem Zool 83: 911 - 923.

Bishop, A., Denton, P., Pomeroy, P., Twiss, S., 2015. Good vibrations by the beach boys: Magnitude of substrate vibrations is a reliable indicator of male grey seal size. Animal Behaviour 100: 74.

Breeding, J. E., Pflug, L. A., Bradley, M., Walrod, M. H. and McBride, W., 1996. Research Ambient Noise Directionality (RANDI) 3.1 Physical Description. Naval Research Laboratory, MS 39529 - 5004. NRL/FR/7176 - - 95 - 9628

Chen, F., Shapiro, G. and Thain, R., 2013. Sensitivity of Sea Surface Temperature Simulation by an Ocean Model to the Resolution of the Meteorological Forcing, ISRN Oceanography, v. 2013: Article ID 215715, 12 pages. doi.org/10.5402/2013/215715

Cronin, M, Jessopp, M and Reid, D., 2010. Seals and Fish Stocks in Irish Waters. Briefing Note to European Parliament Directorate General for Internal Policies. IP/B/PECH/IC/2010 - 
Cunningham, K.A., Southall, B.L. Reichmuth, C. (2014) Auditory sensitivity of seals and sea lions in complex listening scenarios. Journal of the Acoustical Society of America, 136, 340.

Cunningham, K. A., and Reichmuth, C., 2016. High - frequency hearing in seals and sea lions. Hearing Research, 331: 83 - 91.

Ellison, W.T., Southall, B.L., Clark C.W. Frankel A.S. 2011. A new context - based apporach to assess marine mammal behavioural responses to anthropogenic sounds. Conservation Practice and Policy 26, $21-28$.

Erbe, C., MacGillivray, A. and Williams, R. 2012. Mapping cumulative noise from shipping to inform marine spatial planning. J. Acoust. Soc. Am. 132 (5): EL423 - EL428.

Etter, P. C., 2001. Recent advances in underwater acoustic modelling and simulation. Journal of sound and vibration. 240(2), $351-383$.

Francois R. E., Garrison G. R., 1982. Sound absorption based on ocean measurements: Part I:Pure water and magnesium sulfate contributions. Journal of the Acoustical Society of America, 72(3): 896 - 907.

Hamilton, E. L., 1980. Geoacoustic modelling of sea floor. J. Acoust. Soc. Am. 68, 1313.

Hastie, G.D., Russell, D.J.F., McConnell, B, Moss, S., Thompson, D., Janik, V. M., 2015. Sound exposure in harbour seals during the installation of an offshore wind farm: predictions of auditory damage. J App Ecol. 52: 631 - 640 .

IMO 2014 MEPC.1/Circ.833: GUIDELINES FOR THE REDUCTION OF UNDERWATER NOISE FROM COMMERCIAL SHIPPING TO ADDRESS ADVERSE IMPACTS ON MARINE LIFE. Available at http://cetsound.noaa.gov/Assets/cetsound/documents/MEPC.1 Circ\%20883\%20Noise\%20Guidelines\%20April\%202014.pdf

Jensen, F. H., Kuperman, W., A., Porter, M., B. and Schmidt, H., 2011. Computational Ocean Acoustics. Springer, 812p.

Kastak, D., and Schusterman, R. J., 1998. Low - frequency amphibious hearing in pinnipeds: methods, measurements, noise, and ecology. J. Acoust. Soc. Am. 103, 2216 - 2228.

Katsnelson, B., Petnikov V. and Lynch J., 2012, Fundamentals of shallow water Acoustics. Springer, 540p. 
Leeney, R.H., Broderick, A.C., Mills, C., Sayer, S., Witt, M.J., Godley, B.J., 2010. Abundance, distribution and haul - out behaviour of grey seals (Halichoerus grypus) in Cornwall and the Isles of Scilly. J. Mar. Biol. Assoc. UK 90, 1033 - 1040.

Lesage, V., C. Barrette, M. C. S. Kingsley and B. L. Sjare. 1999. The effect of vessel noise on the vocal behavior of belugas in the St. Lawrence River estuary, Canada. Marine Mammal Science 15: $65-84$.

Lynch, J. F., Colosi, J. A., Gawarkiewicz, G. G., Duda, T. F., Pierce, A. D., Badiey, M., Katsnelson, B. G., Miller, J. E., Siegmann, W., Chiu, C. S. and Newhall, A., 2006. Consideration of Fine - Scale Coastal Oceanography and 3 - D Acoustics Effects for the ESME Sound Exposure Model. IEEE Journal of Oceanic Engineering. 31(1), 33 - 48.

Madsen, P. T., Johnson, M., Miller, P. J. O., Soto, N. A., Lynch, J. and Tyack, P., 2006. Quantitative measures of air - gun pulses recorded on sperm whales (Physeter macrocephalus) using acoustic tags during controlled exposure experiments. J. Acoust. Soc. Am. 120(4): 2366 - 2379.

McConnell, B. J., Fedak, M. A., Lovell, P., Hammond, P. S., 1999. Movement and foraging areas of grey seals in the North Sea. J App Ecol 36, 573 - 590.

McDonald, M.A., Hildebrand, J.A., Wiggins, S.M., 2006. Increases in deep ocean ambient noise in the northeast pacific west of San Nicolas Island, California. Journal of the Acoustical Society of America 120 (2), $711-718$.

McKenna, M.F., Ross, D., Wiggins, S.M., Hildebrand, J.A., 2012. Underwater radiated noise from modern commercial ships. Journal of the Acoustical Society of America 131 (1), 92 103.

Merchant, N.D., Witt, M.J., Blondel, P., Godley, B.J., Smith, G.H., 2012. Assessing sound exposure from shipping in coastal waters using a single hydrophone and Automatic Identification System (AIS) data. Marine Pollution Bulletin 64 (7): 1320 - 1329.

MSFD, 2010/477/EU: Commission Decision of 1 September 2010 on criteria and methodological standards on good environmental status of marine waters (notified under document $\mathrm{C}(2010)$ 5956) Text with EEA relevance. Available at http://eur lex.europa.eu/legal - content/EN/TXT/?uri=CELEX:32010D0477(01)/. Accessed 2/2/2016 
Parks, S. E., Johnson, M., Nowacek, D., Tyack P. L., 2011. Individual right whales call louder in increased environmental noise. Biology Letters 7(1): 33 - 35.

Pingree, R. D., 1980. Physical oceanography of the Celtic Sea and English Channel. In: Banner, F.T., Collins, W.B., Massie, K.S. (Eds.), The North - west European Shelf Seas: The Sea Bed and the Sea in Motion II Physical and Chemical Oceanography and Physical Resources. Elsevier, Amsterdam, Oxford, NY, pp. 415 - 465.

Richardson J, Greene C, Malme C, Thomson D., 1995. Marine Mammals and Noise. Academic Press, 525 B Street, San Diego, California 92101 - 4495 USA, ISBN 0 - 12 $588440-0$.

Rolland, R.M., Parks, S.E., Hunt, K.E., Castellote, M., Corkeron, P.J., Nowacek, D.P., Wasser, S.K., Kraus, S.D., 2012. Evidence that ship noise increases stress in right whales. Proceedings of the Royal Society B: Biological Sciences 279 (1737), 2363 - 2368.

Ross, D., 1976. Mechanics of Underwater Noise (Pergamon, New York), pp. 272 - 287.

Russell, D. J. F., McConnell, B. T., 2014. Report to DECC - Seal at-sea distribution, movements and behaviour. Available at https://www.gov.uk/government/uploads/system/uploads/attachment_data/file/346304/OESE A2_SMRU_Seal_distribution_and_behaviour.pdf

Shapiro, G., 2011. Effect of tidal stream power generation on the region - wide circulation in a shallow sea. Ocean Science, 7: 165 - 174.

Shapiro, G., Chen, F., Thain, R., 2014. The effect of ocean fronts on acoustic wave propagation in the Celtic Sea. Journal of Marine Systems. 139: 217 - 226.

Simpson, S. D., Radford, A. N., Holles, S., Ferarri, M. C. O., Chivers, D. P., McCormick, M. I., Meekan, M. G., 2016. Small-Boat Noise Impacts Natural Settlement Behavior of Coral Reef Fish Larvae. Adv Exp Med Biol. 875:1041 - 8.

Southall, B.L., Bowles, A.E., Ellison, W.T., Finneran, J.J., Gentry, R.L., Greene, J., Charles, R., Kastak, D., Ketten, D.R., Miller, J.H., Nachtigall, P.E., Richardson, W.J., Thomas, J.A., Tyack, P. L., 2007. Marine mammal noise exposure criteria: Initial scientific recommendations. Aquatic Mammals, 33(4), 411 - 521.

Sparling, C. E., Fedak, M. A., 2004. Metabolic rates of captive grey seals during voluntary diving. J Exp Biol 207: 1615 - 1624. 
Stansbury, A., Gotz, T., Deecke, V. B., Janik, V. M., 2015. Grey seals use anthropogenic signals from acoustic tags to locate fish: evidence from a simulated foraging task. Proceeding of the Royal Society London B, 282, 20141595.

Thompson, D., 2012. Assessment of Risk to Marine Mammals from Underwater Renewable Devices in Welsh Waters. Phase 2 - Studies of Marine Mammals in Welsh High Tidal Waters on behalf of the Welsh Assembly Governement. Annexe 1 Movements and diving behaviour of juvenile grey seals in areas of high tidal energy. Doc ref JER3688 R 120712 HT Annex 1 Movements and diving behaviour of grey seals.

UKMS, 2014. Marine Strategy Part Two: UK Marine Monitoring Programmes. Available at https://www.gov.uk/government/uploads/system/uploads/attachment_data/file/341146/msfdpart-2-final.pdf

Veirs, S., Veirs, V., Wood, J. D., 2016. Ship noise extends to frequencies used for echolocation by endangered killer whales. PeerJ 4:e1657.

Vincent, C., Fedak, M. A., McConnell, B. J., Meynier, L., Saint-Jean, C., Ridoux, V., 2005. Status and conservation of the grey seal, Halichœrus grypus, in France. Biological Conservation, 126(1), 62-73.

Wale, M. A., Simpson, S. D., Radford, A. N., 2013. Noise negatively affects foraging and antipredator behaviour in shore crabs. Animal Behaviour 86: 111 - 118.

Williams, R., Clark, C. W., Ponirakis, D., Ashe, E., 2014. Acoustic quality of critical habitats for three threatened whale populations, Animal Conservation. http://dx.doi.org/10.1111/acv.12076. 
Table 1 Summary of details of ships and seals

\begin{tabular}{|c|c|c|c|c|c|c|}
\hline & & Name & Length (m) & Horizontal speed & Start time & End time \\
\hline \multirow{2}{*}{ Summer } & Ship & $\begin{array}{l}\text { Auteuil (LPG tanker) } \\
\text { (MMSI: 563483000) }\end{array}$ & 93.0 & 12.2 knots & $\begin{array}{l}21 / 09 / 2011 \\
02: 02: 28\end{array}$ & $\begin{array}{c}21 / 09 / 2011 \\
04: 51: 24 \\
\end{array}$ \\
\hline & Seal1 & hg29-11-10 & N/A & $\begin{array}{l}\text { Mean: } 1.368 \mathrm{~m} / \mathrm{s} \\
\text { Std: } 0.198\end{array}$ & $\begin{array}{c}21 / 09 / 2011 \\
02: 02: 28\end{array}$ & $\begin{array}{c}21 / 09 / 2011 \\
04: 51: 24\end{array}$ \\
\hline \multirow{2}{*}{ Winter } & Ship & $\begin{array}{l}\text { Oscar Wilde (Passenger ship) } \\
\text { (MMSI: } 308847000)\end{array}$ & 166.3 & 15.8 knots & $\begin{array}{c}19 / 12 / 2012 \\
06: 40: 04\end{array}$ & $\begin{array}{c}19 / 12 / 2012 \\
09: 49: 00\end{array}$ \\
\hline & Seal2 & B29 & N/A & Mean: $1459 \mathrm{~m} / \mathrm{s}$ & $\begin{array}{c}19 / 12 / 2012 \\
06: 40: 04\end{array}$ & $\begin{array}{c}19 / 12 / 2012 \\
09: 49: 00\end{array}$ \\
\hline
\end{tabular}

Table 2 Geoacoustic parameters for HARCAM

\begin{tabular}{cccc}
\hline Sediment type & $\begin{array}{c}\text { Sound speed } \\
\text { ratio }\end{array}$ & $\begin{array}{c}\text { Density } \\
\text { ratio }\end{array}$ & $\begin{array}{c}\text { Attenuation of } \\
\text { longitudinal waves } \\
(\mathrm{dB} / \mathrm{m} / \mathrm{kHz})\end{array}$ \\
\hline Clay $^{a}$ & 0.994 & 1.421 & 0.2 \\
Silt $^{a}$ & 1.057 & 1.74 & 0.8 \\
Muddy sand $^{a}$ & 1.115 & 1.856 & 0.67 \\
$\quad$ Sand $^{a}$ & 1.145 & 1.941 & 0.52 \\
Gravelly sand $^{a}$ & 1.201 & 2.034 & 0.46 \\
Sandy Gravel $^{b}$ & 1.250 & 2.1 & 0.4 \\
Chalk $^{b}$ & 1.6 & 2.2 & 0.2 \\
Limestone $^{b}$ & 2.0 & 2.4 & 0.1 \\
\hline
\end{tabular}

${ }^{a}$ Hamilton et al., 1982; ${ }^{b}$ Jensen et al., 2011. 


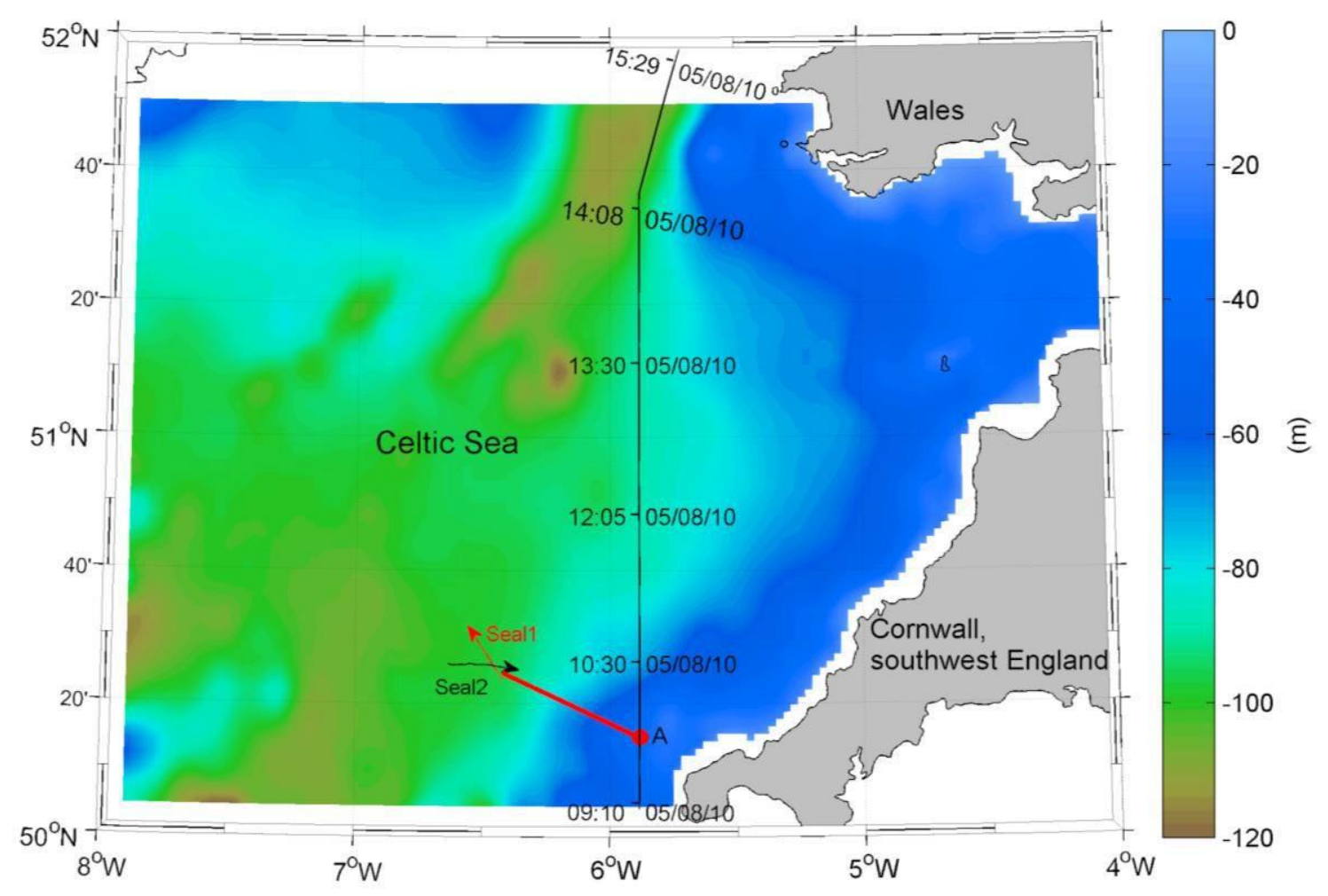

Fig. 1 Study area showing the bathymetry of the model domain. Transect A (thick red solid line) is used to calculate 2D transmission loss. Dot represents the location of the source. Solid line with time stamps express an example of shipping track from a commercial cargo ship (MMSi: 353633000). Arrows represent the horizontal tracks of two seals. 


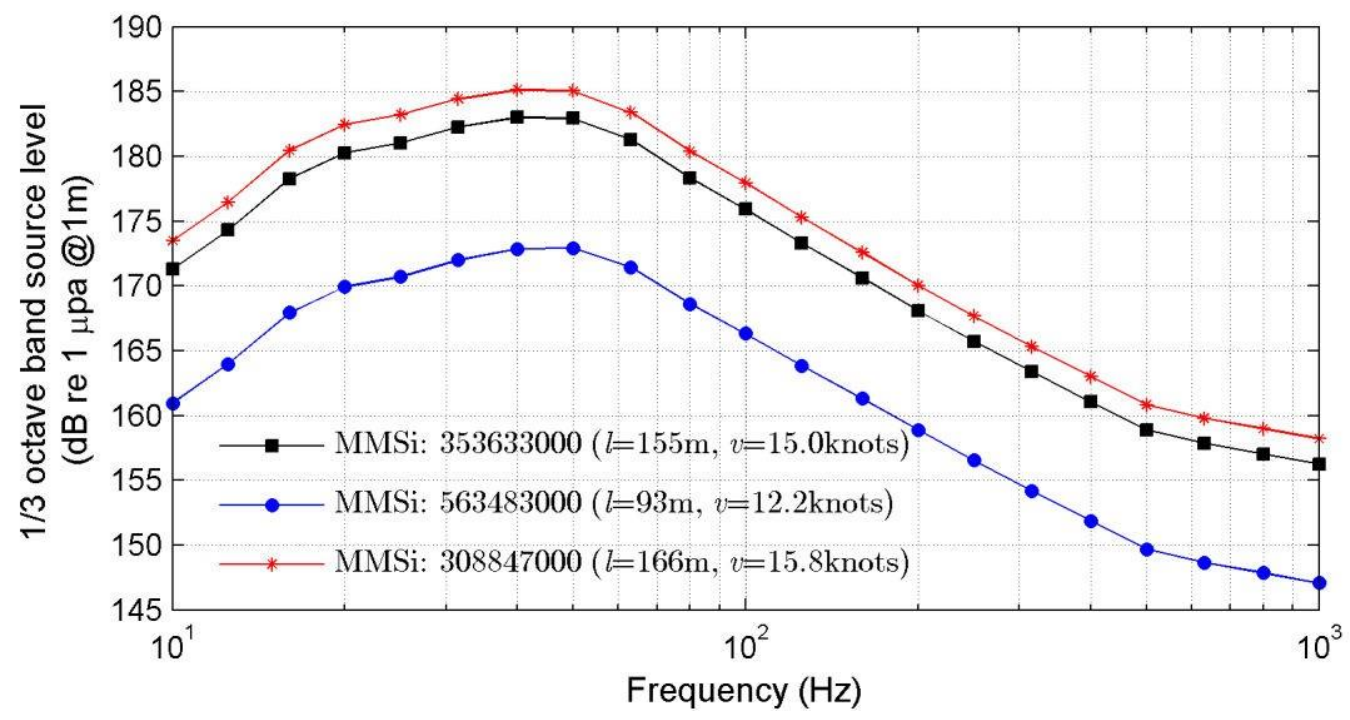

Fig. 2 Source level spectrum in 1/3 octave band radiated by three ships. MMSi: 353633000 (black square) was used to calculate sound exposure levels. MMSi: 563483000 (blue circle) and MMSi: 308847000 (red star) were used to calculate sound pressure levels received by Seal1 and Seal2 respectively. $l$ is ship length and $v$ is averaged operational speed. 

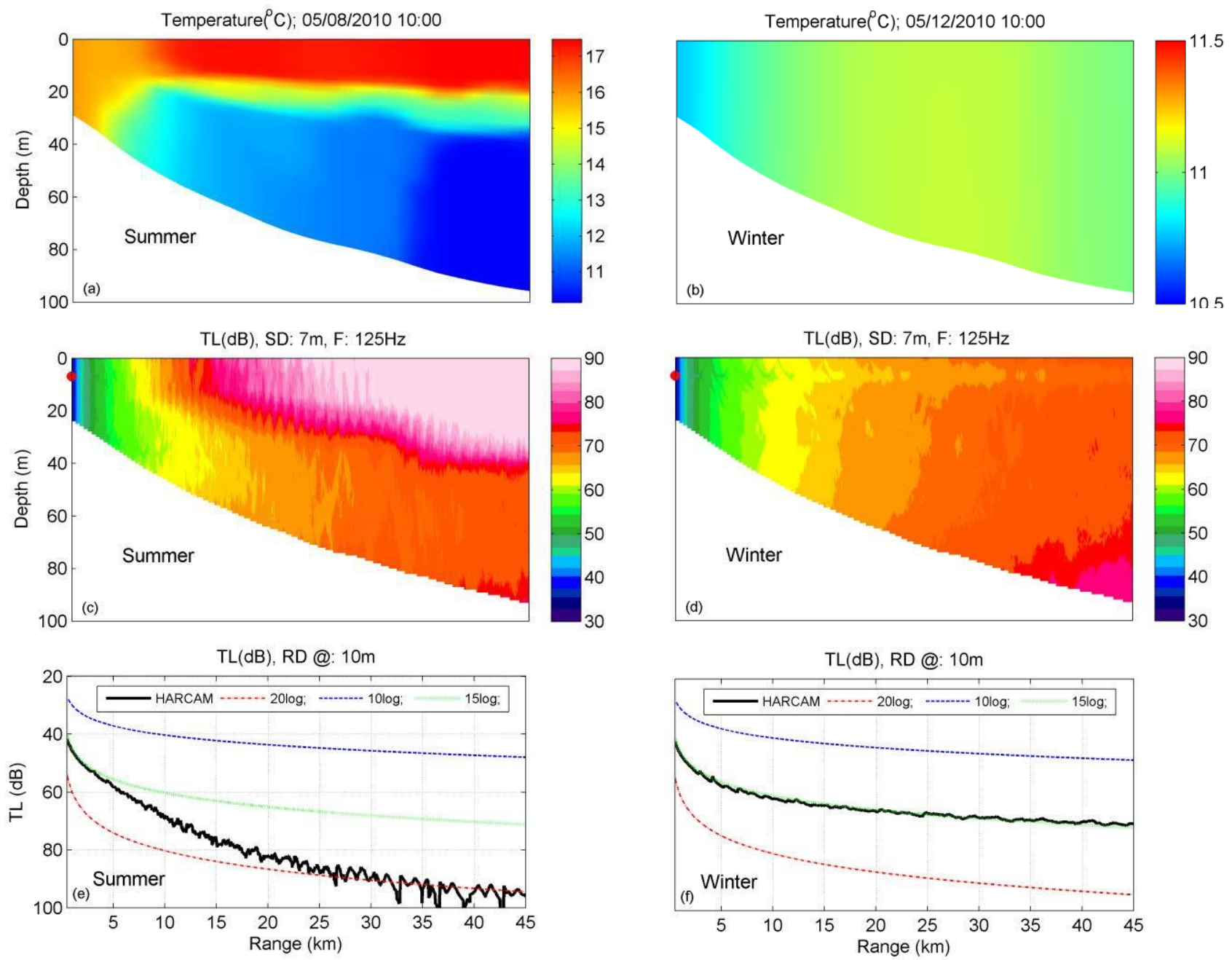

Fig. 3 Seasonal variations of parameters on transect A: (a) and (b): temperature; (c) and (d): transmission loss at frequency $125 \mathrm{~Hz}$ with source $(7 \mathrm{~m})$ located on the onshore side of the bottom front; (e) and (f): comparisons of transmission loss at a water depth of 10m between HARCAM and spreading models (10log, $15 \log$ and $20 \log )$ 

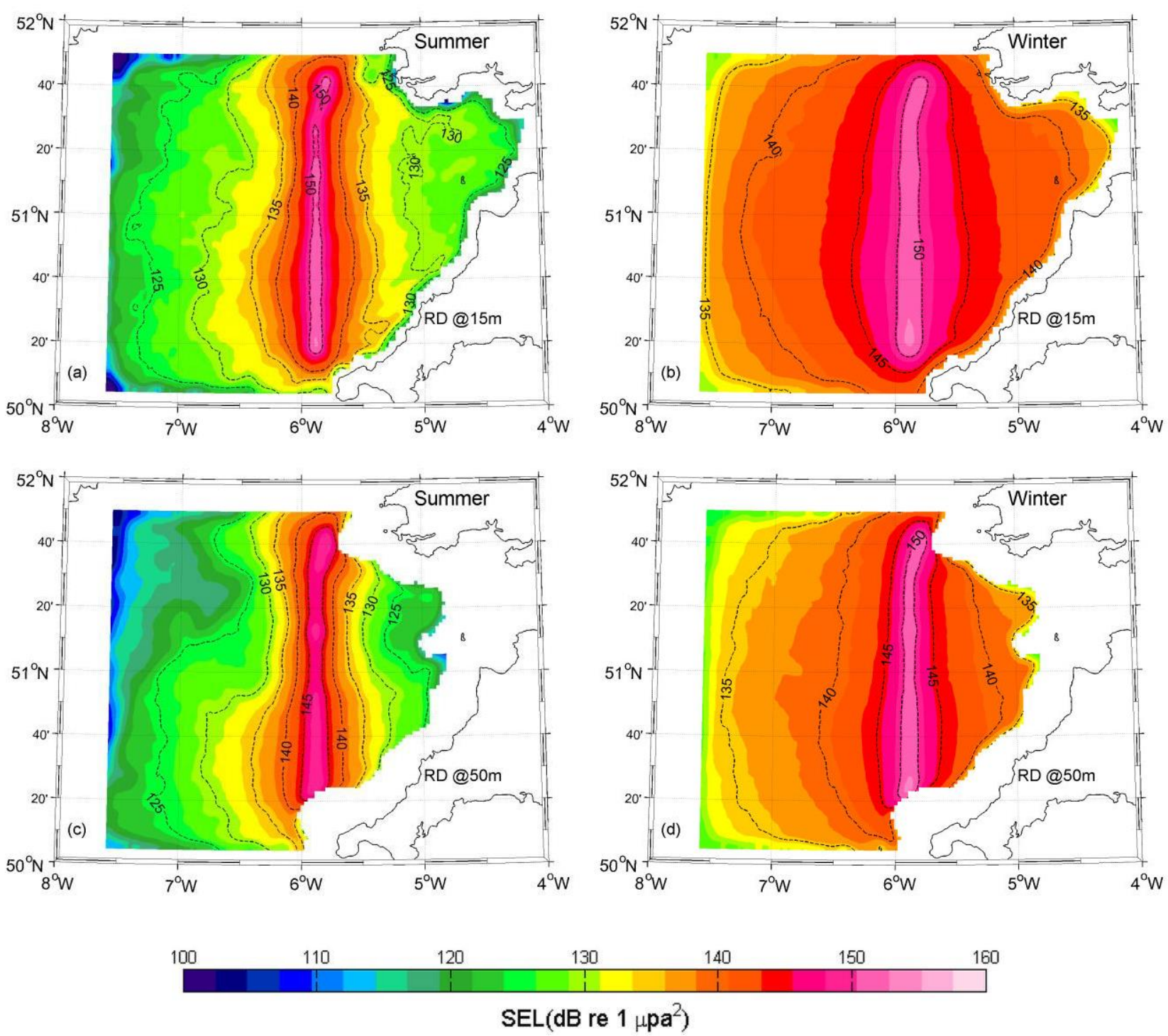

Fig. 4 Sound exposure level with the ship (MMSi: 353633000) travelling northwards over the shipping lane (see Fig. 1) 

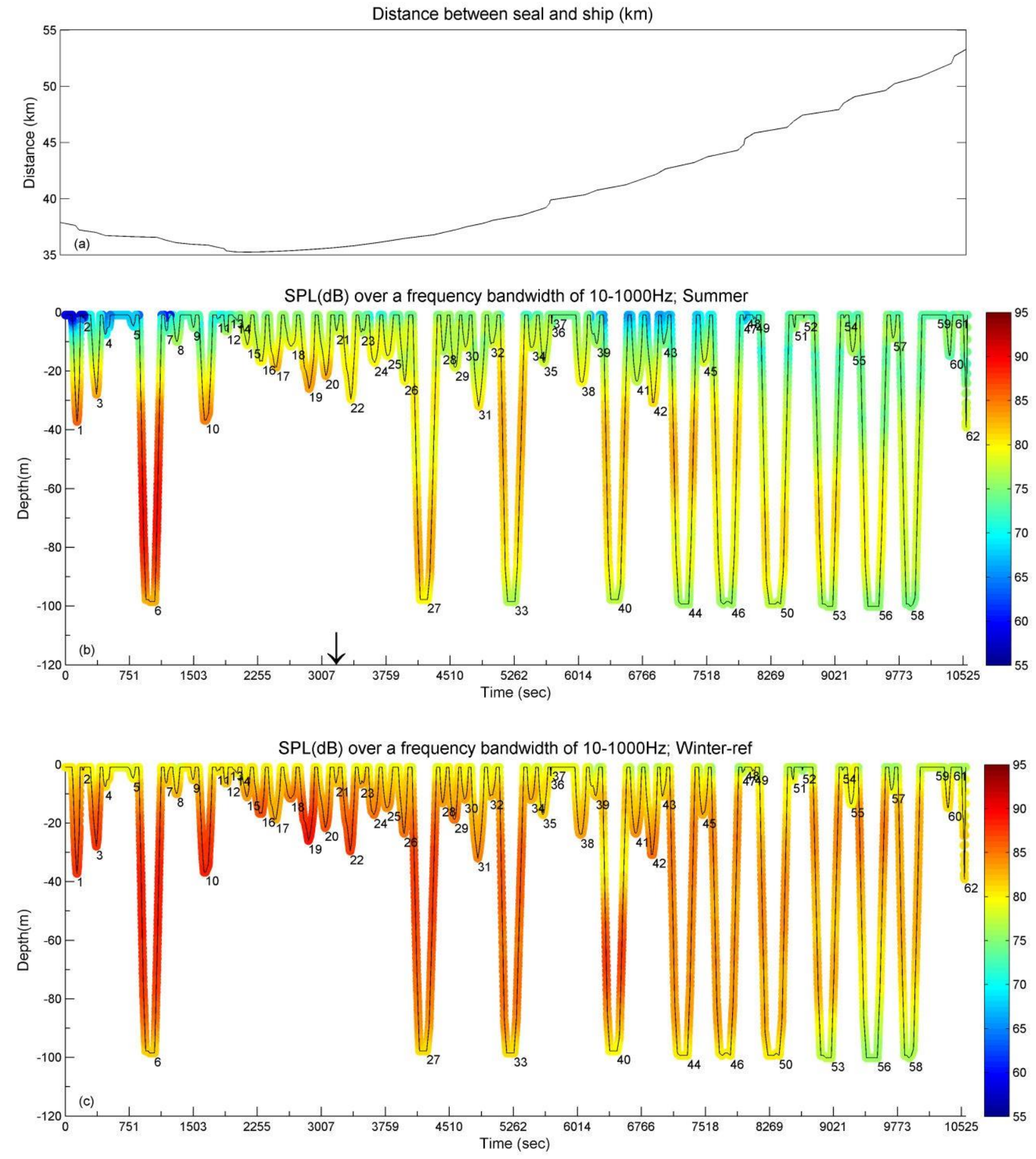

Fig. 5 Sound exposure for Seal1 (see Fig. 1) in summer. (a): relative distance between Seal1 and ship (MMSI: 563483000); (b): SPL (dB) over a frequency bandwidth of 10-1000Hz for Seall over its diving path. The black arrow in the figure marks the time point when the ship crosses the bottom front from onshore to offshore while the numbers are indices of diving profiles; (c): same as (b) with the water column data replaced by winter temperature and salinity for noise calculation 

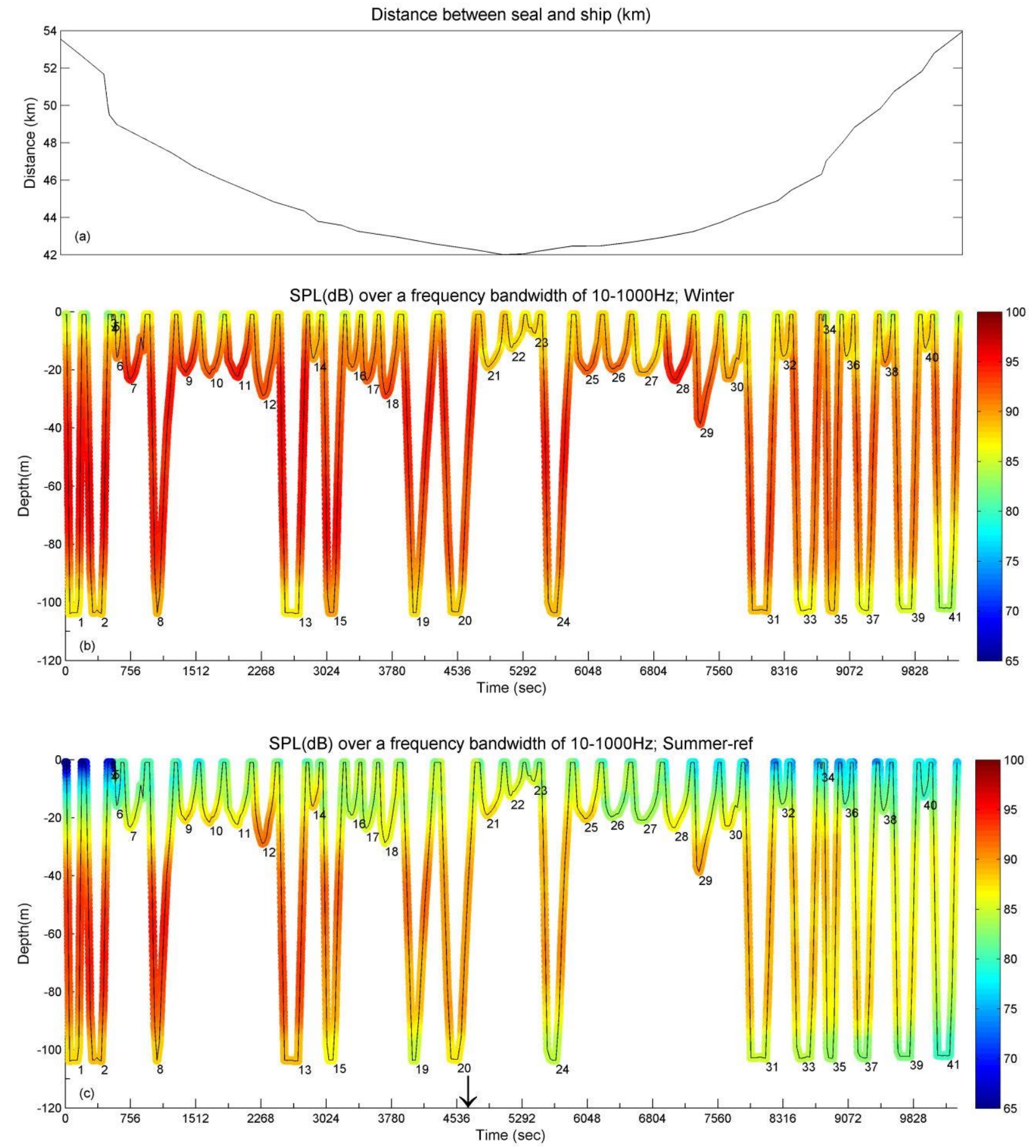

Fig. 6 Sound exposure for Seal2 (see Fig. 1) in winter. (a) Relative distance between Seal2 and ship (MMSI: 308847000); (b) SPL (dB) over a frequency bandwidth of $10-1000 \mathrm{~Hz}$ for Seal2 over its diving path; (c): same as (b) with the water column data replaced by summer temperature and salinity for noise calculation 


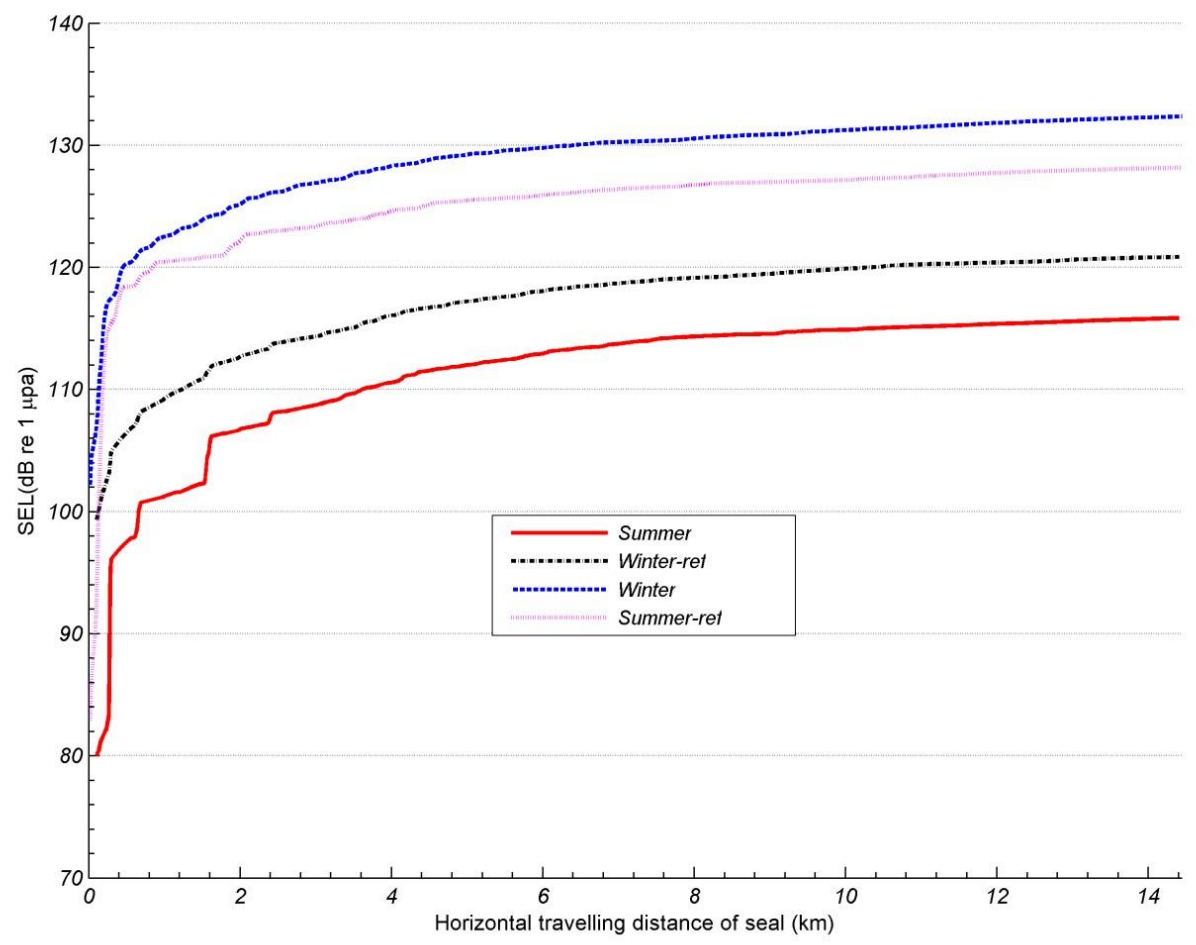

Fig. 7 Cumulative sound exposure levels for Sela1 and Seal2: Seal1 in summer (red solid line), Seal1 in winter (black dot-dash line), Seal2 in winter (blue dashed line) and Seal2 in summer (pink dotted line) 